As the player comes forward from that position the ankle is dorsiflexed and an excessive strain is applied to the calf.

Complete or partial rupture of the Achilles tendon may also present with sudden, acute pain in the calf, and these are the alternative diagnoses which must be excluded. The patient should be examined lying supine or kneeling on a chair. First the musculo-tendinous junction of the gastrocnemius must be palpated for evidence of local tenderness, swelling, or a gap in the muscle. Then the tendon should be made taut by resisting the voluntary action of the calf with one hand on the sole of the foot, and the tendon should be palpated with the other hand for evidence of rupture or local tenderness or swelling within the tendon. R. Ljungqvist ${ }^{3}$ has recently provided an excellent report on partial rupture of the Achilles tendon, including coloured photographs of his operative findings.

For treatment of tennis leg Froimson recommends immediate raising of the leg and application of ice bags. After that he advocates rest, with crutches and no weight-bearing for 24 to 36 hours, and no tennis for about five weeks. When walking is first attempted the heel of the shoe is raised temporarily by $\frac{3}{4}$ to 1 in. $(1.5$ to $2.5 \mathrm{~cm}$.).

Just as "tennis elbow" is an unsatisfactory name in that it

\section{Life on Mars?}

In 1900 a Madame Goguet left 100,000 francs to the French Academy of Sciences to be given to whoever established communication with another world "other than Mars." Evidently Mars was considered too easy a target to be worth such an exorbitant sum-then equivalent to about $£ 4,000-$ and the reason must have been the "canals"-those unnaturally straight, thin lines whose problematical existence has been the subject of controversy ever since the Italian astronomer Schiaparelli thought he had observed them in $1878 .^{2}$ Yet even now, after the passage of the two Martian probes, Mariner 6 and 7, which took photographs of the planet's surface from only 2,000 miles away and transmitted them to earth, we must still wait for the pictures to be " tidied up " by computer before being sure what they reveal. The trouble is that radio interference produced odd spots and patches on the pictures which upset their clarity. But some areas of the surface were fortunately included in several photographs, so, if a process akin to visual superposition is applied, after correcting for distortion caused by differing angles of view, the genuine features will thereby be enhanced, while the spurious marks, being different in each photograph, will fade into the background and, we are told, can even be eliminated by the computer.

The greatest advocate of the theory that the "canals" are evidence of intelligent life was Percival Lowell, who built an observatory in the clear air of Arizona specially to study the planets. In three books ${ }^{3-5}$ he developed the idea that, as the Martian surface dried up in course of time, its inhabitants developed a scheme for conveying water from each melting polar ice-cap in the spring to the rest of the corresponding hemisphere, and that the visible signs of this operation were not the actual waterways but belts of vegetation on either side of them. (Lowell did not live to see the recent photo- is seldom caused by playing tennis, so the term "tennis leg" could be criticized on the grounds that it is a relatively common type of muscle injury caused by many other activities. However, it is too late to complain. In 1884 Wharton P. Hood ${ }^{4}$ described "lawn-tennis leg" as follows: "The great popularity of lawn-tennis has given the above name to an accident which has long been known to surgeons, but which the particular kind of effort required by the game has of late years rendered much more frequent than heretofore. It consists of the rupture of some portion of the muscular or tendinous structure of the calf." Surprisingly the case he describes fully is that of Dr. W. G. Grace, who was playing cricket at Lords on 12 June 1884 and had made 60 runs, when he had the sudden feeling of being smartly struck in the calf. He thought he was done for the season and dared not put his heel to the ground to save his life. Mr. Hood examined him and felt a distinct sulcus as he passed his finger down the calf. According to his custom Mr. Hood elevated the leg, applied firm strapping from the ankle to the knee, and told him to be as active as possible. The next day Dr. Grace completed his innings at Lords and never rested his leg a single day. Two weeks after the injury he scored 107 runs against the Australians at the Oval. graphs of the earth taken by American astronauts in orbit, in which the course of the Nile can be traced from the belts of vegetation alongside the river.)

The "canal" theory lost favour as more and more astronomers declared themselves unable to see these features, and it was pointed out that the human eye, when straining to see something on the verge of visibility, is apt to join up visible features with imaginary lines. As drawn by Lowell and his followers, the "canals" usually start and end at prominent features on the edges of the dark areas of Mars, or at smaller dark spots which Lowell termed " oases."

These darker areas cover about one-third of the planet's surface and undergo changes remarkably like those of vegetation. Their broad shapes remain unchanged, but their detailed outlines undergo visible changes from one Martian year to the next. Furthermore, their colour varies with the seasons. They are faint in the winter, but then darken to a blue-green colour which first appears in high latitudes and gradually spreads towards the equator, as if stimulated by water vapour from the polar ice-caps spreading through the atmosphere. Then-most remarkably of all-their colour changes to brown. Unfortunately for the vegetation theory, this does not happen in autumn but in late spring and early summer. The nearest earthly equivalents to this change appear to be some species of lichen, which turn from greygreen to brown when drying out in bright sunlight. ${ }^{6}$ However, these areas do not show the spectrum of chlorophyll, which lichens contain in their algal cells.

There are two theories favouring a non-biological explanation of the colour changes in the dark areas. One is that certain minerals darken when moist; this would account for the change spreading from pole to equator as the ice-caps melt. The other theory postulates volcanoes. D. B. McLaughlin ${ }^{\tau}$ drew attention to the roughly similar shapes of the dark areas and the fact that many of them end in a sharp 
point. If one postulates a volcano at each point belching forth dark matter, and trade winds on Mars resembling those on the earth, the shapes would be accounted for. Furthermore, they would be dimmed in summer by dust blown in from the bright "desert" areas.

Oddly enough, the Mariner photographs so far published show no details of the distribution of the dark matter in these areas, though "splotchy" features on the track of alleged canals, already seen by some post-Lowell astronomers, have been confirmed. But other types of observation by these probes have made unexpected discoveries of biological interest about the Martian atmosphere, much to the excitement of the newspapers as the pendulum swung alternately against and in favour of the possibility of life. The lack of Jxygen was already known, but though our own oxygen is accepted as the product of photosynthesis this does not preclude the possibility of photosynthesis on Mars, because, as H. Strughold ${ }^{8}$ and others have suggested, the plants could keep within their tissues the oxygen which they produce.

Perhaps the most surprising of the Mariner discoveries about the Martian atmosphere is the entire absence of nitrogen, and as our own atmospheric nitrogen is believed to have come mainly from volcanoes McLaughlin's improbable theory will have to go. More remarkable is the deduction that this deficiency may preclude the development of life on the planet. The argument is derived from S. L. Miller's ${ }^{9}$ demonstration in 1953 that amino-acids can be produced by sending electric discharges through an imitation of the earth's primitive atmosphere, consisting mainly of nitrogen and carbon dioxide. Other organic chemicals, such as the constituents of nucleic acid, have now been produced by similar means, and the idea that these substances made possible the development of life on the earth is at present widely accepted. On the other hand, there is spectroscopic evidence from Mariner 7 of ammonia and methane, or some higher hydrocarbon, in the region bordering the south polar cap.

Present opinion is coming to regard the dark areas as raised above the level of the surrounding " deserts." One elongated patch even sets up a stationary cloud to leeward, ${ }^{10}{ }^{11}$ marking the crest of a stationary "mountain lee wave" of the type first exploited and brought to the notice of meteorologists by glider pilots. And another thing: when glider pilots look for upward curents of warm air ("thermals") on earth they find that vegetation is cooler than bare ground. But astronomers found many years ago that the Martian dark areas are hotter than the deserts, sometimes by as much as $10^{\circ} \mathrm{C}$. On earth an excess temperature of $1^{\circ} \mathrm{C}$. is enough to start a thermal. So in the absence of oxygen to burn fuel gliders may yet serve as a means of transport on Mars, though they would need six times as strong an upcurrent as on earth to sustain them in the thin atmosphere.

1 Ley, W., and von Braun, W., The Exploration of Mars. London, Sidgwick and Jackson. 1956 .

- Schiaparelli, G. V., Osservazioni astronomiche $e$ fisiche sull asse di rotazione e sulla topografia del pianeta Marte. Rome, Reale Accademia dei Lincei. 1878.

s Lowell, P., Mars. London, Longmans, Green. 1896.

- Lowell, P., Mars and its Canals. London, Macmillan. 1907.

- Lowell, P., Mars as the Abode of Life. London, New York, Macmillan. 1909.

- Smith, Annie L., Lichens. Cambridge University Press. 1921.

7 McLaughlin, D. B., The Observatory, 1954, 74, 197.

- Strughold, H., The Green and Red Planet. Albuquerque, University of New Mexico Press. 1953.

- Miller, S. L., Science, 1953, 117, 528.

10 Wells, R. A., Nature, 1965, 207, 735.

11 Slater. A. E., Sailplane and Gliding, 1965, 16, 409.

\section{Rosacea-like Dermatitis}

Under the name "light-sensitive seborrhoeid" this disease was first reported from the U.S.A. in 1957. ${ }^{1}$ Further reports from the States"-4 came under the titles "dermatitis of the nasolabial folds," " perioral dermatitis," and "facial dermatitis of unknown cause." In $1968^{\circ}$ came an account of 40 cases from Denmark and England, the term "perioral dermatitis" being adopted. Now comes a report of a much larger series of patierts (115) from West Germany, ${ }^{6}$ and here the name "rosacea-like dermatitis" is used. All these titles are descriptive only, for the cause of the disease is unknown. It is known to be fairly frequent also in South Africa, so that it occurs regularly on at least three continents.

All the descriptions of the disease are remarkably similar, and there seems to be no doubt that it is one which, if not new, is becoming much more frequently recognized. The eruption appears in cycles, and each cycle is composed of three phases. The first phase appears abruptly, with patches of closely packed, pointed papules and at times papulo-vesicles or papulo-pustules. The papules measure $1-3 \mathrm{~mm}$. at their bases. The appearance at this stage is that of an allergic contact dermatitis, but pruritus is slight or absent. The second phase occurs after five to ten days. The papules are flattened and the sites present an erythematous, scaly appearance. The morphology now closely resembles seborrhoeic dermatitis, a resemblance which is heightened by the presence of seborrhoea capitis in many cases. The third stage consists of residual erythema. The cycles are repeated at irregular intervals for months or years and may overlap, so that all stages are sometimes present together. The location is characteristic. It affects the chin in all cases and usually the nasolabial folds. There is often a clear zone 5 to $7 \mathrm{~mm}$. wide separating the eruption from the lip margin. Less often the lower parts of the cheeks and the inner aspects of the eyebrows are involved.

It most frequently affects females $20-45$ years of age, but no age is exempt and a few cases occur in men ; 12 of the 115 West German patients were male. Though light sensitivity was considered to be an important feature of its causation in the first series, this has not been confirmed in later reports. Premenstrual flare has been noted in some cases. Extensive patch-testing has failed to show that any particular cosmetics cause it, but the German report notes that the condition is commonest in patients who use cosmetics and body-care preparations extensively. It suggests that these patients may have a constitutional predisposition to the disease. Reports on the histopathology have not been helpful ; they disclose only a mild subacute inflammation with a variable follicular and perifollicular infiltrate. The condition has to be differentiated from acne, seborrhoeic dermatitis, contact dermatitis, and rosacea.

It is remarkably resistant to treatment. Some patients are made worse by sulphur preparations as used for acne or rosacea, and many fail to respond to topical corticosteroids. If used for too long, these may induce telangiectasia and

\footnotetext{
Frumess, G. M., and Lewis, H. M., Archives of Dermatology, 1957,
75, 245.

Kaufman, W. H., Virginia Medical Monthly, 1963, 90, 275.

s Mihan, R., and Ayres, S., Archives of Dermatology, 1964, 89, 803.

- Kaufman, W. H., fournal of the American Medical Association, 1965, 192, 252.

' Hjorth, N., Osmundsen, P., Rook, A. J., Wilkinson, D. S., and Marks, R., British fournal of Dermatology, 1968, 80, 307. - Steigleder, G. K., Deutsche Medizinische Wochenschrift, 1969, 94,
} 